\title{
A PAROSTEAL LIPOMA
}

\section{H. A. Thomas Farbaik, LoNinos, EN(iLANi)}

The recent publication in the Journal of a case of lipoma causing a lesion of the posterior interosseous nerve (Richmond 19.73) prompts me to report a similar case seen in 19:2 7 in which the same nerve seemed to be involved, but without interference with its function.

Case report - A man of tifty-eight rears complained of a lump on the outer side of his right forearm which he had noticed for the past three weeks. His only complaint was that for some time past, when playing the piano, his arm got tired. There was an obvious swelling on the outer side of the forearm in the upper third. The swelling was firm with a slightly. irregular surface which was rather elastic in the middle but not actually fluctuant: below, the swelling ended rather abruptly. It was not tender. It was covered by the muscles and rotated with the radius. There were no large veins or other visible changes in the arm, and no paralysis. The radiograph showed a bilobed translucent area in the muscles beside a normal radius (Fig. 1), so a diagnosis of lipoma was made. At operation the tumour was found buried beneath the fibres of the supinator brevis muscle. As the position and direction of the deep groove in the surface of the tumour suggested that this wats produced by the posterior interosseous nerve it was decided that it would be wiser to leave this part of the capsule intact. The lipoma was divided a little below this groove, and removed in two parts, the upper being slipped from beneath the nerve without difficulty. I few outlying nodules of fat were found lying posterior to both lobes of the main tumour. The periosteum covering the radius was intact. Examination of the forearm later revealed no sign of nerve damage.

Comment-Parosteal was the term used by

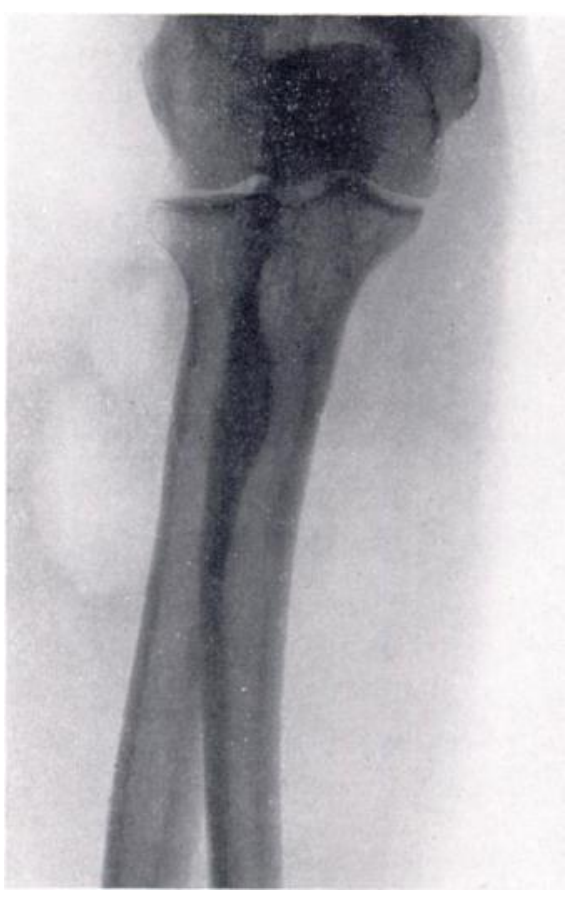

IFIG. 1

Radiograph showing the bilobed radiotranslucent tumour adjacent to the upper third of the radius.

D'Arcy Power in 1888 when he reported a case of lipoma growing beside a femur. In his book on Tumours, Bland-Sutton (19066) cited fourteen cases, including three of his own, of "parosteal lipomata" which he regarded as "arising from the periosteum." In only one of these cases was the radius the bone involved (Smith 1868 ). This was in a boy of nine vears with a lump the size of a man's fist which had been growing for six years: on remoral of the tumour the neck of the radius was bare and "beset with minute spicules." $N_{0}$ mention is made of any paralysis. Parosteal seems preferable to periosteal as applied to these lipomata, and both terms seem to be more accurate than subperiosteal.

\section{REFERENCES}

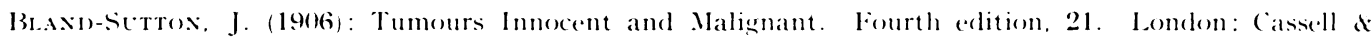
Company I.imited.

l'ow:k, I)'Are (1888): A Parosteal I.ipoma, or Congenital Fatty Tumour, Connected with the l'eriosteum of the Femur. Transactions of the Pathological society of london, 39, 270.

Richuoxin, 1). . (1953): I ipoma (ausing a l'osterior Interosseous Nerve Iesion. Journal of Bone and Joint surgery, $35 \mathrm{~B}, 83$.

SMrt, T. (1868): Fatty. Tumour (irowing from the Neck of the Radius. Transactions of the Iatholegical society of london, 19, 344.

V(1. $35 \mathrm{~B}$, N(). 4, NONEMHER 1953 